Check for updates

Cite this: RSC Adv., 2017, 7, 51257

\title{
Alkylmethylimidazolium tricyanomethanide based supported ion gel membranes for $\mathrm{CO}_{2}$ separation $\uparrow$
}

\author{
Yongha Hwang, $\$^{a}$ Eunhae Cho, $\stackrel{t}{a}^{a}$ Jiyoon Jung, ${ }^{a}$ Yong Soo Kang $\mathbb{D}^{\mathrm{b}}$ \\ and Jongok Won (DD *a
}

Supported ion gel membranes (SIGMs) with good mechanical stability for $\mathrm{CO}_{2}$ separation were prepared using triblock copolymers in an ionic liquid (IL). lon gels were obtained by the addition of a small amount of poly(styrene-block-ethylene oxide-block-styrene) (SEOS) copolymer in the 1-alkyl-3methylimidazolium tricyanomethanide family ([RMIm][TCM], with alkyl group R = ethyl (E), butyl (B) and hexyl $(H))$, and their properties were investigated. Mechanically stable SIGMs were prepared by selfassembly of [RMIm] [TCM]/SEOS solution on the surface of the porous support, and their $\mathrm{CO}_{2}$ separation performances were measured. The ideal $\mathrm{CO}_{2} / \mathrm{CH}_{4}$ separation factors were 9.7, 12.3 and 11.2 for the SIGMs containing [EMIm][TCM], [BMIm][TCM] and [HMIm][TCM], respectively. Morphological structure and complex formation, as determined by wide-angle $\mathrm{X}$-ray diffraction analysis and theoretical calculations, respectively, were conducted to study the permselectivity. The SIGM of [BMIm][TCM] shows a higher selectivity than that of [EMIm] [TCM], since the interaction with $\mathrm{CO}_{2}$ of $[\mathrm{EMIm]}[\mathrm{TCM}]$ is stronger than that of [BMIm] [TCM] or [HMIm][TCM] and the large intermolecular distance of [EMIm] [TCM] leads to the non-selective structure for $\mathrm{CO}_{2}$ transport.

Received 19th August 2017

Accepted 30th October 2017

DOI: 10.1039/c7ra09171k

rsc.li/rsc-advances used in SILMs and demonstrated the phase dependence on the permselectivity of the gas.

In SILMs, the RTIL is typically trapped inside the pores ${ }^{8}$ and acts as a selective layer. Although the low vapor pressure of the RTIL provides higher stability than that of the common supported liquid membrane (SLM) that usually has a volatile liquid phase, the improvement of the tolerance under a pressure difference for the practical gas separation is still necessary because the liquid-phase of ILs inside of the pores leaches out during operation (Fig. 1a). ${ }^{1}$

To circumvent this limitation, the fabrication of solid or pseudo-solid membranes, such as polymerized RTIL-based membranes, ${ }^{\mathbf{1 0 , 1 1 , 1 8}}$ dispersed membranes using physical or chemical interaction with the matrix and ILs ${ }^{12,13,19-22}$ or polymer gel $^{23}$ has been considered. While the stability of the membrane is improved by changing the phase of the ILs from liquid to solid, the gas transport is also changed. When a carrier is present in the liquid phase of the membrane, IL will interact specifically with $\mathrm{CO}_{2}$ and form an $\mathrm{IL}-\mathrm{CO}_{2}$ complex carrier. Then, the $\mathrm{IL}-\mathrm{CO}_{2}$ complex carrier diffuses through the liquid phase of the membrane and then releases the $\mathrm{CO}_{2}$ downstream. Therefore, the interaction (characterized by solubility of $\mathrm{CO}_{2}$ in ILs) as well as the diffusivity of the carrier in the liquids determines the permselectivity. On the contrary, when the carrier is fixed to a solid phase of the membrane, the mobility of the carrier is restricted and the $\mathrm{CO}_{2}$ molecules must hop among the different sites during transport. Therefore, the interaction between the carrier and $\mathrm{CO}_{2}$ must be reversible for a solid phase
${ }^{a}$ Department of Chemistry, Sejong University, 209 Neungdong-ro, Gwangjin-gu, Seoul 05006, South Korea. E-mail: jwon@sejong.ac.kr; Fax: +82-2-3408-4317; Tel: +82-23408-3230

${ }^{b}$ Department of Energy Engineering, Hanyang University, 222 Wangsimni-ro, Seongdong-gu, Seoul 04763, Korea

$\dagger$ Electronic supplementary information (ESI) available. See DOI: 10.1039/c7ra09171k

\$ Yongha Hwang, Eunhae Cho contributed equally. 

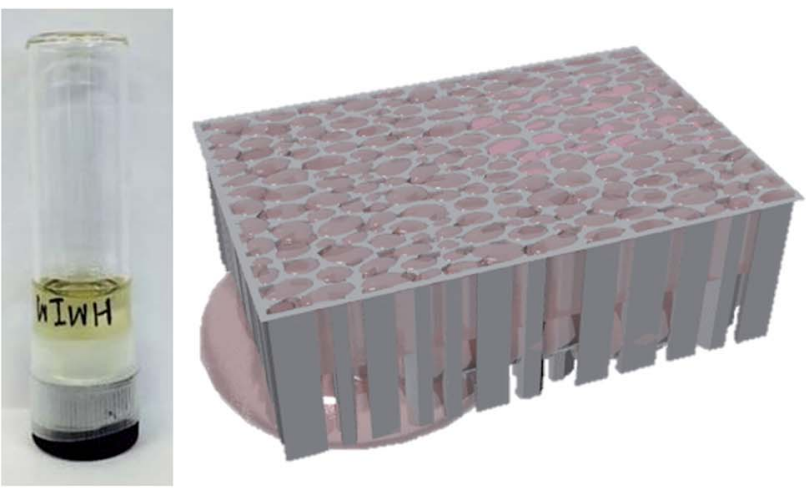

(a)
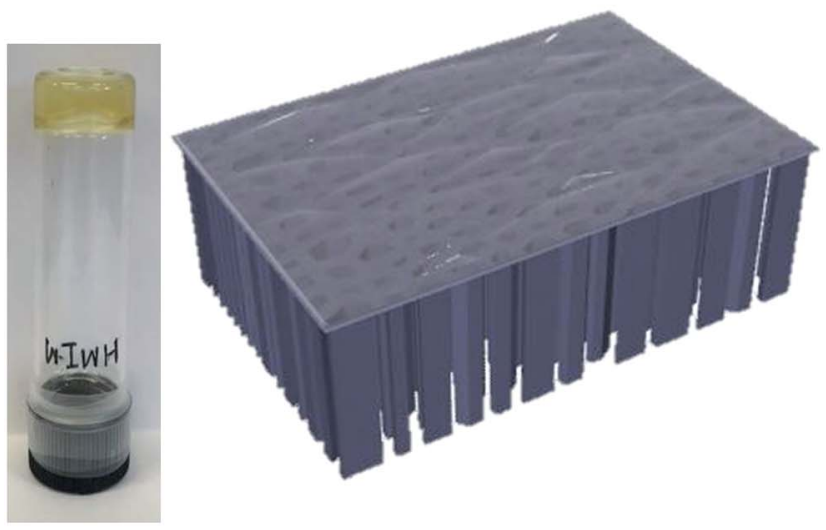

(b)

Fig. 1 Models and photographs of (a) SILM using [HMIm][TCM] ionic liquid and (b) SIGM using [HMIm][TCM] ion gel.

facilitated transport membrane, otherwise, $\mathrm{CO}_{2}$ will not transport when all carriers have formed complexes with $\mathrm{CO}_{2}$.

Generally, $\mathrm{CO}_{2}$ transport is higher in the liquid phase than in the solid phase, and the gas diffusion in the solid phase depends on the segmental mobility of the matrix polymer. That is, the solidification of the medium would provide the stability of the membrane while it lost the high diffusivity of the liquid. Therefore, it is necessary to prepare a membrane matrix that is mechanically stronger than SILM but that still retains the property of the liquid. The fabrication of a supported ion gel membrane (SIGM) is one approach for achieving this goal as shown in Fig. 1b; SIGM preserves the diffusion properties of the gases in the liquid phase of the RTILs while possessing a higher mechanical strength.

A much smaller amount of poly(styrene-block-ethylene oxideblock-styrene) (SEOS) copolymer was needed (as low as $5 \mathrm{wt} \%$ ) to form a gel, ${ }^{19,20,23,24}$ compared to the general polymer gels that require $10-30 \mathrm{wt} \%$ of additional polymers. ${ }^{24}$

The choice of RTIL is also important. Therefore, we chose an IL based on the alkylmethylimidazolium [RMIm] cations with tricyanomethanide ([TCM]) anion to obtain both a high gas permeability and gas permselectivity among the various RTILs tested so far for SILMs. ${ }^{25-28}$ Tomé et al. prepared a SILM using porous hydrophilic poly(tetrafluoroethylene) membranes and evaluated the relationship between the physical properties and transport properties. ${ }^{28}$ Tzialla et al. prepared zeolite imidazolate frameworks interacting with 3-methyl-1-octyl-imidazolium tricyanomethanide and found that these materials exhibit high $\mathrm{CO}_{2} / \mathrm{N}_{2}$ selectivity under the transmembrane pressure of 200 $\mathrm{kPa} .{ }^{29}$ In this study, we prepared SIGMs using a porous nylon support (Fig. 1b) and investigated their permselectivity.

\section{Experimental section}

\section{Materials}

The ionic liquids, 1-ethyl-3-methylimidazolium tricyanomethanide ([EMIm][TCM]), 1-butyl-3-methylimidazolium tricyanomethanide ([BMIm][TCM]), and 1-hexyl-3-methylimidazolium tricyanomethanide ([HMIm][TCM]), (Future Chem. Co., Ltd., Korea), poly(styrene- $b$-ethylene oxide- $b$-styrene) (SEOS, P-8872, $M_{\mathrm{w}}=50 \mathrm{~kg} \mathrm{~mol}^{-1}$, weight fraction of PEO $=60 \%$ ) (Polymer Source, Inc) and dichloromethane $\left(\mathrm{CH}_{2} \mathrm{Cl}_{2}\right)$ (Aldrich Co.) were purchased and used as received. Porous nylon membrane supports with pore sizes of $100 \mathrm{~nm}$ (Magna Nylon Membrane Filters, Krackeler Scientific, Inc.) were used as the support for the membrane fabrication.

\section{Preparation of the membranes}

SIGMs were prepared by pouring $15 \mathrm{wt} \%$ [RMIm][TCM]/SEOS solution in $\mathrm{CH}_{2} \mathrm{Cl}_{2}$ onto the surface of the nylon supports. $5 \mathrm{wt} \%$ of SEOS was added in the [RMIm][TCM]. The total amount of [RMIm][TCM]/SEOS loading on the nylon support was fixed at approximately $0.027 \mathrm{~g} \mathrm{~cm}^{-2}$ for all samples. After the solvent, $\mathrm{CH}_{2} \mathrm{Cl}_{2}$ was evaporated at room temperature for $24 \mathrm{~h}$, the membrane was put in a vacuum oven to dry completely until a constant weight was obtained. For reproducibility, at least three SIGMs were prepared. SILMs were also fabricated by impregnating the [RMIm][TCM] onto porous nylon supports for comparison.

\section{Characterization}

The permeance of different gases $\left(\mathrm{CO}_{2}, \mathrm{~N}_{2}\right.$ and $\left.\mathrm{CH}_{4}\right)$ was measured using a soap bubble flow meter ${ }^{30}$ at room temperature and $207 \mathrm{kPa}$. The ideal separation factor $\left(\mathrm{CO}_{2} / \mathrm{CH}_{4}\right.$ or $\mathrm{CO}_{2} /$ $\mathrm{N}_{2}$ ) was determined from the ratio of pure gas permeance. The microstructure of the ion gel was determined at ambient temperature by wide-angle X-ray diffraction analysis (WAXD) with a Rigaku D/MAX-2500/PC using Ni-filtered $\mathrm{Cu} \mathrm{K}_{\alpha}$ radiation at the scanning rate of $5^{\circ} \mathrm{min}^{-1}$. Thermal properties were determined by differential scanning calorimetry (DSC, Perkin Elmer, Inc.) at the heating rate of $10^{\circ} \mathrm{C} \mathrm{min}^{-1}$. The morphology of the SIGM surfaces was measured with a Hitachi S- 4700 field emission scanning electron microscope (SEM).

\section{Computational method}

The fully optimized structures and electronic energy of ILs and the $\mathrm{IL} \cdots \mathrm{CO}_{2}$ complex in the gas phase were obtained with the Gaussian 09 software package ${ }^{31}$ using the density functional 
theory method with the B3LYP hybrid exchange-correlation functional and $6-31+\mathrm{G}(\mathrm{d}, \mathrm{p})$ basis set. ${ }^{32-34}$ The details of the procedure used to obtain the optimized structure are provided in the ESI. $\dagger$ Although it is known that the calculations with the basis set superposition error correction by the counterpoise method could provide the more consistent result with the experimental data, ${ }^{35,36}$ we considered only the uncorrected complexation energy between the molecules for computational efficiency because our objective here was to see the trend of the interaction between the $\mathrm{CO}_{2}$ and ILs.

\section{Results and discussion}

Yellowish transparent [RMIm][TCM]/SEOS ion gels were formed by adding $5 \mathrm{wt} \%$ of SEOS into each [RMIm][TCM], and the ion gels are shown in Fig. 2. It is known that the formation of a gel is due to the microsegregation of the styrene in the SEOS copolymer. $^{23}$

To examine the interaction between the SEOS and the [RMIm][TCM], the thermal properties of the [RMIm][TCM]/ SEOS ion gels were measured by DSC and the results are shown in Fig. 3 with the DSC curve for the SEOS copolymer film.

The melting temperature of the SEOS copolymer is $51.75^{\circ} \mathrm{C}$, which is known to be due to the crystalline property of ethylene oxide in SEOS, the SEOS peak is not observed for all [RMIm] [TCM]/SEOS ion gels. This may be due to the ion-dipole interaction between the [RMIm] cations and oxygen in the SEOS copolymer, which would imply the miscibility between [RMIm] [TCM] and SEOS. ${ }^{23,37}$

SIGMs were prepared using different [RMIm][TCM]/SEOS ion gels. The surface images of the porous support and SIGM prepared with [BMIm] [TCM]/SEOS ion gels investigated by SEM are shown in Fig. 4.

While the surfaces of the pristine nylon support showed pores, the surface images of the SIGM with the [BMIm][TCM]/ SEOS ion gel investigated by SEM show that all of the pores are covered. It is same for all other SIGMs having different [RMIm][TCM]. Since $95 \mathrm{wt} \%$ of the ion gel are liquid-phase $[\mathrm{RMIm}][\mathrm{TCM}]$, the preparation of the fractured SIGM sample

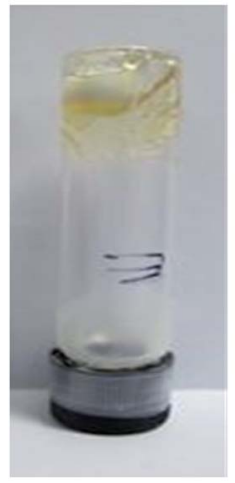

(a)

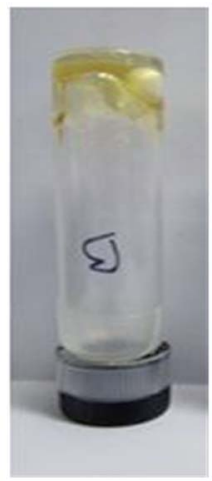

(b)

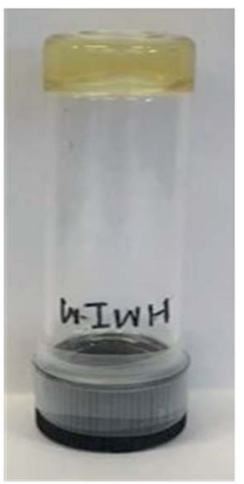

(c)
Fig. 2 Images of ion gels of (a) [EMIm][TCM]/SEOS, (b) [BMIm] [TCM]/ SEOS and (c) [HMIm] [TCM]/SEOS.

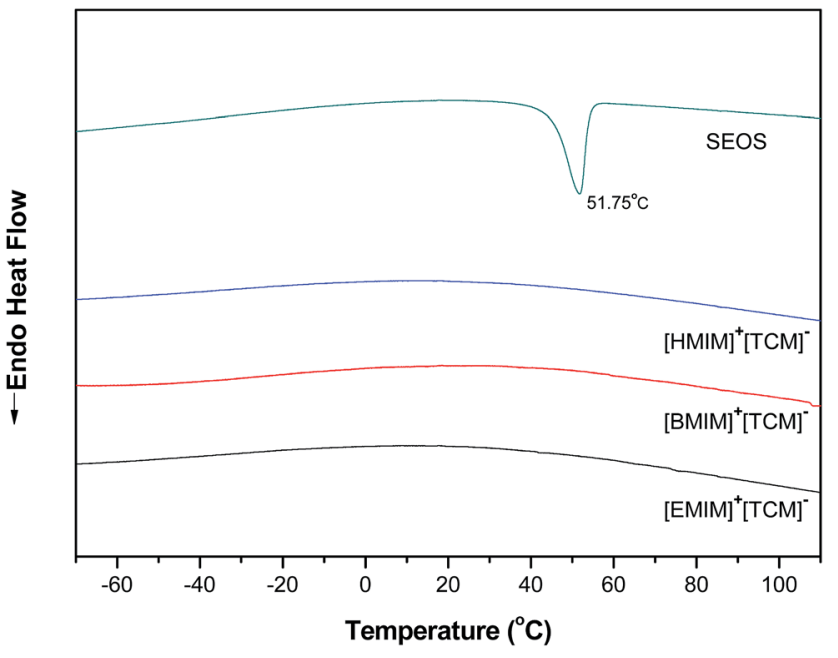

Fig. 3 DSC analysis of SEOS, [EMIm] [TCM], [BMIm] [TCM] and [HMIm] [TCM] ion gels containing 5 wt\% SEOS (second heating step).

was not succeeded, so it was impossible to investigate the crosssectional information of the SIGM such as the thickness of the selective ion gel layer.

The $\mathrm{CO}_{2}$ permeance and the ideal selectivities $\left(\mathrm{CO}_{2} / \mathrm{CH}_{4}\right.$ or $\mathrm{CO}_{2} / \mathrm{N}_{2}$ ) for three different SIGMs are shown in Fig. 5. Although SILMs were also prepared for the comparison, we were not able to obtain reproducible data because a burst out was observed. By contrast, for all SIGMs, the gas permeance was maintained during the measurement time at $207 \mathrm{kPa}$ flow conditions.

Although the thickness of the selective ion gel layer was not determined by SEM, it is estimated to be $c a$. $240 \mu \mathrm{m}$ by a simple calculation using the density value for ILs $\left(1.0738 \mathrm{~g} \mathrm{ml}^{-1}\right.$ for the case of [EMIm][TCM]), ${ }^{16}$ under the assumption that all ILs exist on the surface of the support. Due to the uncertainty in the thickness value of the selective ion gel layer, it is impossible to compare the permeance directly, but it is clear that all three membranes show $\mathrm{CO}_{2}$ permeance values of the same order.

The ideal $\mathrm{CO}_{2} / \mathrm{CH}_{4}$ selectivity was 9.7 for the SIGM with the [EMIm][TCM]/SEOS ion gel, which is lower than the reported value of 19.4 for the SILM prepared in porous hydrophilic pol$y$ (tetrafluoroethylene); ${ }^{28}$ this finding is probably due to the use of a different support and preparation method. The ideal $\mathrm{CO}_{2} /$ $\mathrm{CH}_{4}$ selectivities were 12.3 and $\mathbf{1 1 . 2}$ for the SIGM with the [BMIm] [TCM]/SEOS and the [HMIm][TCM]/SEOS SIGM, respectively. The order of ideal $\mathrm{CO}_{2} / \mathrm{CH}_{4}$ selectivities is [BMIm] $[\mathrm{TCM}]>[\mathrm{HMIm}][\mathrm{TCM}]>[\mathrm{EMIm}][\mathrm{TCM}]$, and the trend of the selectivities is consistent with the results obtained when the IL was confined in a small pore of inorganic support (i.e., SILM). ${ }^{\mathbf{1 6}}$ This agreement is probably due to the fact that the gas transport would mainly follow the liquid-phase mechanism because $95 \mathrm{wt} \%$ of the ion gel has a liquid phase, despite the presence of two phases in ion gels.

The viscosity is reported to be $14.48,27.84$ and $41.95 \mathrm{mPa} \mathrm{s}$ for [EMIm][TCM], [BMIm][TCM], [HMIm][TCM], respectively. ${ }^{25}$ In general, the gas permeance in the liquid phase is higher than that in the solid phase, therefore, lower viscosity of [EMIm] 


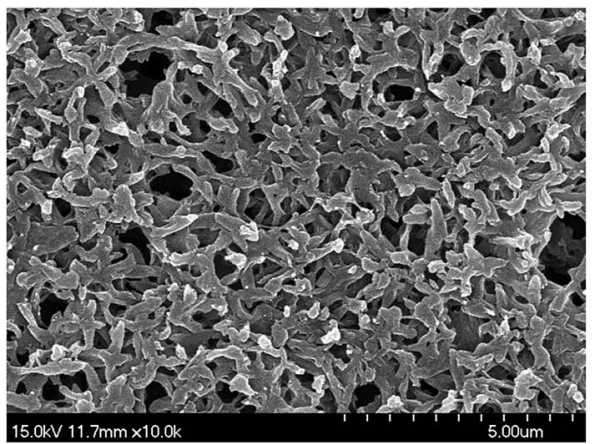

(a)

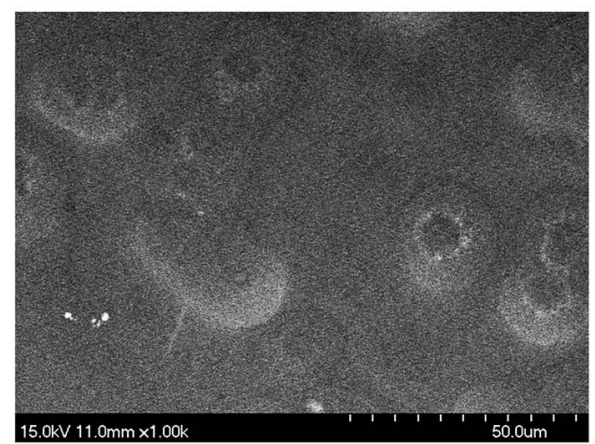

(b)

Fig. 4 Surface image of (a) support nylon membrane and (b) SIGM using the [BMIm][TCM]/SEOS ion gel observed by SEM.

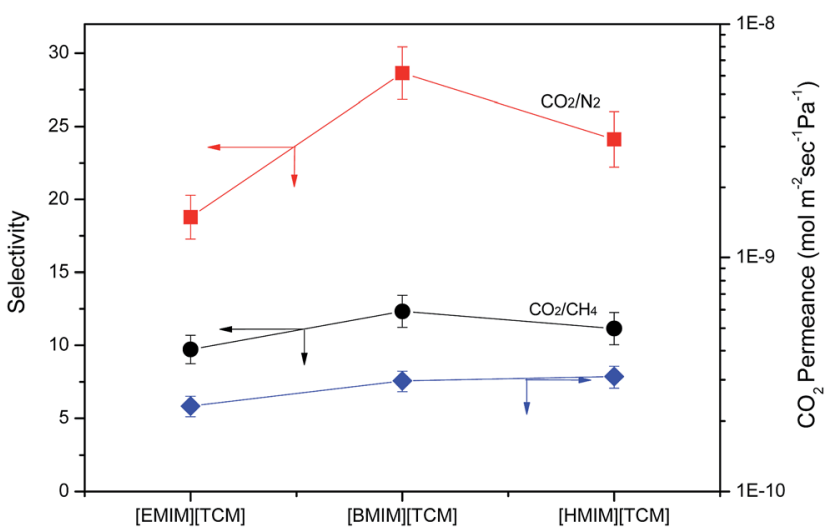

Fig. $5 \mathrm{CO}_{2}$ permeance and ideal selectivity of $\mathrm{CO}_{2} / \mathrm{CH}_{4}$ (and $\left.\mathrm{CO}_{2} / \mathrm{N}_{2}\right)$ SIGM containing of [RMIm] [TCM] ion gel.

[TCM] would have a positive effect on the $\mathrm{CO}_{2}$ separation. However, both the SILM and the SIGM with [EMIm][TCM] have the lowest permselectivity irrespective of whether the phase of the selective layer is liquid or solid-like. This finding implies that the viscosity is not the main factor for the selectivity.

X-ray diffraction pattern was obtained to investigate the morphology of the ion gels by WAXD because the gas separation also depends on the microstructure of the matrix in facilitated transport membrane. The results are shown in Fig. 6.

Two sharp peaks of the crystalline PEO block in SEOS films at $2 \theta=18.3^{\circ}$ and $22.4^{\circ},{ }^{37-39}$ disappear in the WAXD spectrum of the [RMIm] [TCM]/SEOS ion gels due to the interaction between the [RMIm] cation and the oxygen of the EO segment of SEOS. While a broad peak is observed in the $10-35^{\circ}$ range implying that an ordered structure was formed instead. A broad peak is observed for the [BMIm][TCM]/SEOS and [HMIm][TCM]/SEOS ion gels, while two broad peaks are observed at $2 \theta=17.5^{\circ}$ and $24.8^{\circ}$ for the $[\mathrm{EMIm}][\mathrm{TCM}] / \mathrm{SEOS}$ ion gel.

It is known that the $d$-spacing corresponds to the intermolecular distance that is related to the diffusion of the gases and determines the permselectivity. The $d$-spacing calculated using Bragg's law $(n \lambda=2 d \sin \theta$, where $n, \lambda$ and $\theta$ are an integer, wavelength, and the angle, respectively) for the [EMIm][TCM]/
SEOS is 0.36 and $0.51 \mathrm{~nm}$, whereas 0.39 and $0.40 \mathrm{~nm}$ are obtained for the ion gel of [BMIm][TCM]/SEOS and [HMIm][TCM]/ SEOS, respectively. While it can be understood that the $d$ spacing depends on the size of the cation of RTILs, the high value of $0.51 \mathrm{~nm}$ in [EMIm] [TCM] is rather intriguing. Considering the kinetic diameters of $\mathrm{CO}_{2}, \mathrm{~N}_{2}$ and $\mathrm{CH}_{4}$ of $0.330,0.364$, and $0.380 \mathrm{~nm}$, respectively, the two different $d$-spacings of [EMim][TCM]/SEOS affect the diffusivity and structural selectivity of gases significantly, unlike those of the [BMIm][TCM]/ SEOS or [HMIm] [TCM]/SEOS ion gels.

To determine the structural difference between [EMIm] [TCM] and [BMIm][TCM] or [HMIm][TCM], the B3LYP structure of [RMIm] $[\mathrm{TCM}]$ and the interaction between $\mathrm{CO}_{2}$ and the IL were calculated using Gaussian 09 software ${ }^{31}$ using density functional theory (ESI $\dagger$ ).

The calculated B3LYP ${ }^{32,33}$ structure of [RMIm] [TCM] is shown in Fig. 7. The optimized structures for [EMIm][TCM] (Fig. 7a) indicate that the nonbonding interactions between the three $\mathrm{N}$ atoms of $\left[\mathrm{C}(\mathrm{CN})_{3}\right]^{-}$and the three hydrogen atoms of [EMIm].

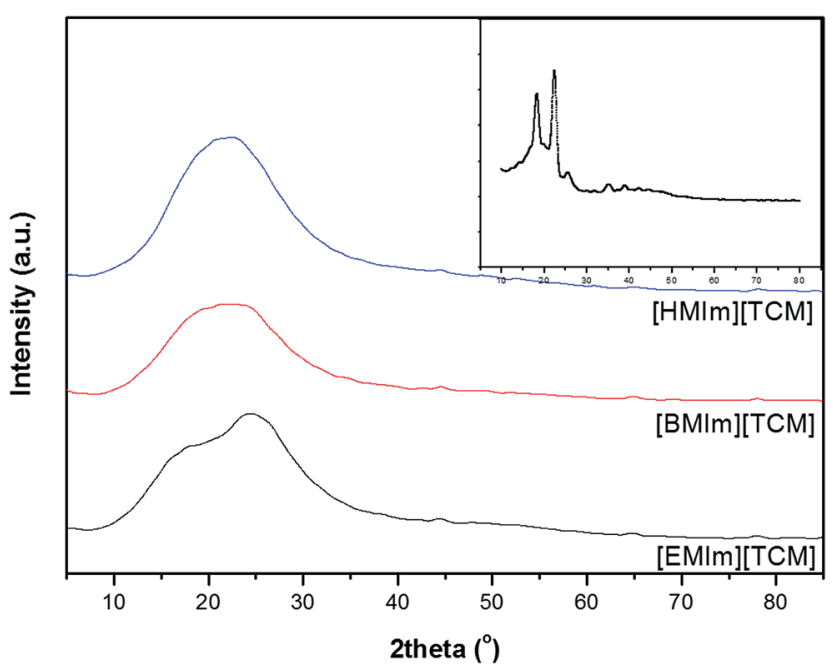

Fig. 6 WAXD curves for [EMIm][TCM], [BMIm] [TCM] and [HMIm] [TCM] ion gels containing $5 \mathrm{wt} \%$ of SEOS. Inset shows the WAXD curve of the SEOS film. 


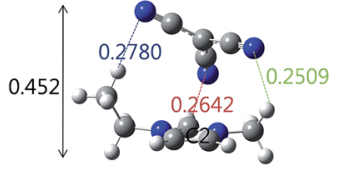

(a)

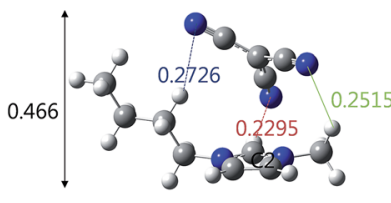

(c)

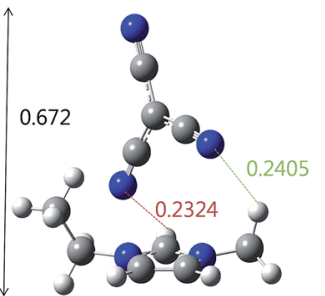

(b)

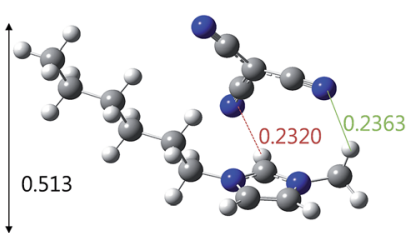

(d)
Fig. 7 Optimized ((B3LYP)/6-31+G(d,p)) structure of the most stable (a), (b) [EMIm] [TCM], (c) [BMIm] [TCM] and (d) [HMIm] [TCM] (unit is nm)

[BMIm] [TCM] (Fig. 7c) and [HMIm] [TCM] (Fig. 7d) are also present in a similar structure to that of [EMIm][TCM]; however, for the case of [EMIm][TCM], there are other stable optimized conformers in which the anion position is vertical to the planar imidazolium cation (Fig. 7b). Because the difference in the energy between structures Fig. $7 \mathrm{a}$ and $\mathrm{b}$ is less than $2.5 \mathrm{~kJ} \mathrm{~mol}^{-1}$, it is expected that the two conformers are randomly distributed in a real system for [EMIm][TCM].

These two conformers exhibit different ordering distances ( 0.452 and $0.672 \mathrm{~nm}$ for conformers a and $\mathrm{b}$, respectively), as shown in Fig. 7a and b, which would explain the two different microstructure determined by the WAXD experiment; furthermore, the higher $d$-spacing due to the conformer b (Fig. 7b) provides a longer $d$-spacing that reduces the selectivity.

To examine the interaction between the [RMIm] $[\mathrm{TCM}]$ and $\mathrm{CO}_{2}$, four different stable complexes of $\mathrm{CO}_{2}$ with [EMIm][TCM]
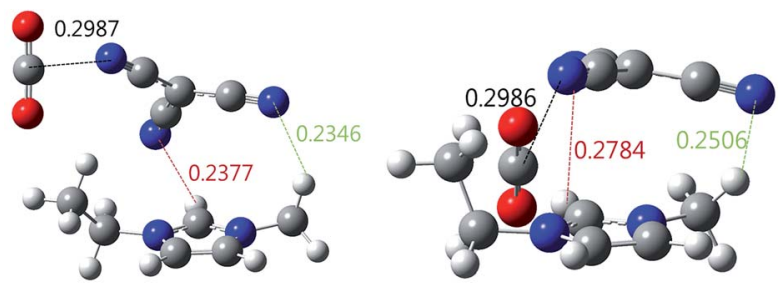

(a) I

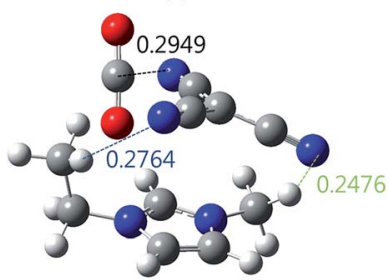

(c) III (b) II

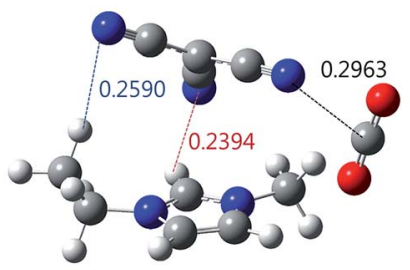

(d) IV
Fig. 8 Optimized ((B3LYP)/6-31+G(d,p)) structure of complexes with [EMIm] [TCM] $\cdots \mathrm{CO}_{2}$ : (a) I, (b) II, (c) III and (d) IV (unit is nm). were obtained and are shown in Fig. 8. The details of the procedure used for the optimization of these structure are provided in the ESI. $\dagger$ One of the stable complexes is located close to the ethyl group of [EMIm] (I), the second (II) and third (III) are located between the ethyl and methyl groups of [EMim] in the opposite direction, and the fourth (IV) is close to the methyl group of [EMIm]. The most stable complex structure [EMIm] $]$ TCM $] \cdots \mathrm{CO}_{2}$ is complex (I).

The B3LYP structures of [BMIm] [TCM $] \cdots \mathrm{CO}_{2}$ and [HMIm] $[\mathrm{TCM}] \cdots \mathrm{CO}_{2}$ were calculated using a similar method. The optimized structures with $\mathrm{CO}_{2}$ were obtained in a similar position to those of $\mathrm{CO}_{2}$ in [EMim] [TCM].

The complexation energy $\left(\Delta E_{\mathrm{c}}\right)$ defined as the difference between the energy of the [RMIm] [TCM $\cdots \mathrm{CO}_{2}$ adduct and the sum of the energies of the separate [RMIm][TCM] and $\mathrm{CO}_{2}$ in the gas phase and the results are shown in Fig. 9.

With the exception of complex (I), there is no significant complexation energy difference with the number of carbon atoms in the cation of IL. The $\Delta E_{\mathrm{c}}$ values were found to be $-18.73,-10.04$ and $-10.35 \mathrm{~kJ} \mathrm{~mol}^{-1}$ for the [EMIm][TCM] $\cdots$ $\mathrm{CO}_{2},[\mathrm{BMIm}][\mathrm{TCM}] \cdots \mathrm{CO}_{2}$ and $[\mathrm{HMIm}][\mathrm{TCM}] \cdots \mathrm{CO}_{2}$ complexes of structure (I) in the gas phase, respectively, indicating that the formation of [EMim][TCM] $\cdots \mathrm{CO}_{2}$ is more favorable than the formation of a complex containing a higher number of carbon atoms in [RMIm]. This result is consistent with the reported trend of the enthalpy of solvation; the value was $-12.99,-12.58$ and $-12.07 \mathrm{~kJ} \mathrm{~mol}^{-1}$, for [EMIm][TCM], [BMIm][TCM], and [HMIm] [TCM], respectively. ${ }^{25}$ While the experimental $\mathrm{CO}_{2}$ solubility depend on the free volume rather than the interaction between the IL and $\mathrm{CO}_{2}$, the solubility increased with increasing alkyl chain length of the imidazolium cation. The solubility were reported to be $0.016,0.024$ and $0.030 \mathrm{~mol} \mathrm{~mol}^{-1} \mathrm{bar}^{-1}$ for [EMIm][TCM], [EMIm][TCM], [EMIm][TCM], respectively. ${ }^{16}$ It is known that the interaction between the carrier inside a matrix and $\mathrm{CO}_{2}$ must be optimal; otherwise, if the interaction is too strong, $\mathrm{CO}_{2}$ transport will stop when all carriers form complexes with $\mathrm{CO}_{2}$. The weaker interaction between the RTIL and $\mathrm{CO}_{2}$ of $[\mathrm{BMIm}][\mathrm{TCM}]$ relative to that of $[\mathrm{EMIm}][\mathrm{TCM}]$ would provide a positive effect on the facilitated $\mathrm{CO}_{2}$ transport. In summary, [EMIm][TCM] shows a stronger interaction than those of

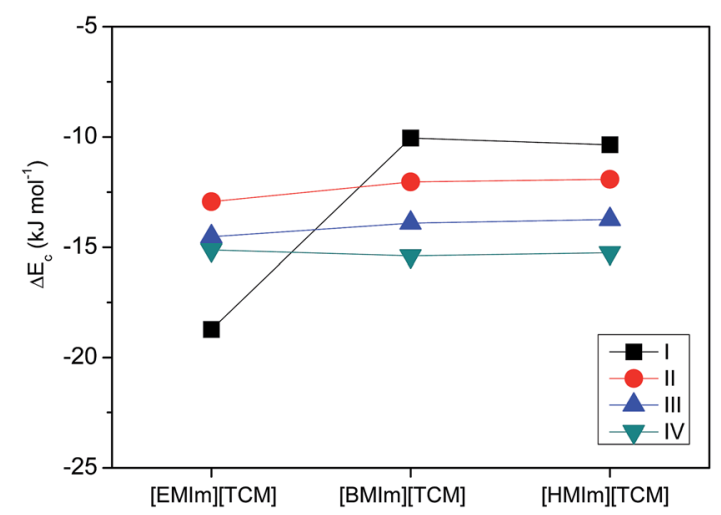

Fig. 9 Complexation energy $\left(\Delta E_{c}\right)$ in the gas phase of four different stable complexes of $\mathrm{CO}_{2}$ with [RMIm] [TCM]. 
[BMIm][TCM] or [HMIm][TCM], and the larger $d$-spacing than those of transport gases reduces the permselectivity despite the lowest viscosity of [EMIm][TCM]. Therefore, the membrane containing [BMIm][TCM] showed the higher permselectivity both in the SILM and the SIGM.

\section{Conclusions}

We prepared SIGMs incorporating alkylmethylimidazolium tricyanomethanide ion gels with the addition of a small amount of SEOS for $\mathrm{CO}_{2}$ separation; the obtained material retained the advantages of the liquid phase of the RTIL, such as high diffusion, while showing enhanced mechanical strength under high pressure operation conditions. A theoretical study was conducted to determine the effect of the number of $\mathrm{C}$ atoms in alkylmethylimidazolium tricyanomethanide on the structure, interaction with $\mathrm{CO}_{2}$, and the complexation energy for the $\mathrm{CO}_{2}$ carrier. The [BMIm] [TCM]/SEOS ion gel-based SIGM exhibited high $\mathrm{CO}_{2} / \mathrm{N}_{2}\left(\mathrm{CO}_{2} / \mathrm{CH}_{4}\right)$ ideal selectivity which is consistent with those in SILM. This high permselectivity was understood using WAXD experiments and theoretical calculations. Due to the short chain of R in [EMIm][TCM], the formation of two ordered structures is possible (one is selective and the other is nonselective for the $\mathrm{CO}_{2}$ transport), which reduces the permselectivity. The combination of a solid-like high mechanical stability and maintenance of the liquid-like high gas permeability in the SIGM together with the permselectivity consistent with that of the SILM makes these membranes valuable new platforms for $\mathrm{CO}_{2}$ separation systems.

\section{Conflicts of interest}

There are no conflicts to declare.

\section{Acknowledgements}

This work was supported by the Korea CCS R\&D Center (KCRC) grant funded by the Korean government (Ministry of Science, ICT \& Future Planning) (Grant no. NRF-2014M1A8A1049313), by the Basic Science Research Program through the National Research Foundation of Korea (NRF) (NRF-2014R1A1A3050640 and NRF-2017R1A2B4004737).

\section{References}

1 R. E. Baltus, R. M. Counce, B. H. Culbertson, H. Luo, D. W. DePaoli, S. Dai and D. C. Duckworth, Sep. Sci. Technol., 2005, 40, 525-541.

2 C. Wang, X. Luo, H. Luo, D. E. Jiang, H. Li and S. Dai, Angew. Chem., Int. Ed., 2011, 50, 4918-4922.

3 A. L. Miller, T. K. Carlisle, A. L. LaFrate, B. A. Voss, J. E. Bara, Y. C. Hudiono, B. R. Wiesenauer, D. L. Gin and R. D. Noble, Sep. Sci. Technol., 2012, 47, 169-177.

4 C. Wang, X. Luo, X. Zhu, G. Cui, D. Jiang, D. Deng, H. Li and S. Dai, RSC Advances, 2013, 3, 15518-15527.

5 C. Wu, T. P. Senftle and W. F. Schneider, Phys. Chem. Chem. Phys., 2012, 14, 13163-13170.
6 M. S. Shannon, J. M. Tedstone, S. P. Danielsen, M. S. Hindman, A. C. Irvin and J. E. Bara, Ind. Eng. Chem. Res., 2012, 51, 5565-5576.

7 C. Cadena, J. S. Anthony, J. K. Shah, T. I. Morrow, J. F. Brennecke and E. J. Maginn, J. Am. Chem. Soc., 2004, 126, 5300-5308.

8 P. Scovazzo, J. Membr. Sci., 2009, 343, 199-211.

9 P. Luis, L. A. Neves, C. A. M. Afonso, I. M. Coelhoso, J. G. Crespo, A. Garea and A. Irabien, Desalination, 2009, 245, 485-493.

10 J. E. Bara, T. K. Carlisle, C. J. Gabriel, D. Campe, A. Finotello, D. S. Gin and R. D. Noble, Ind. Eng. Chem. Res., 2009, 48, 2739-2751.

11 W. Zhao, G. He, L. Zhang, J. Ju, H. Dou, F. Nie, C. Li and H. Liu, J. Membr. Sci., 2010, 350, 279-285.

12 P. Cserjési, N. Nemestóthy and K. Bélafi-Bakó, J. Membr. Sci., 2010, 349, 6-11.

13 D. D. Iarikov, P. Hacarlioglu and S. T. Oyama, Chem. Eng. J., 2011, 166, 401-406.

14 F. F. Krull, M. Hechinge, W. Kloeckner, M. Verhuelsdonk, F. Buchbender, H. Giese and T. Melin, Colloids Surf., A, 2009, 345, 182-190.

15 O. C. Vangeli, G. E. Romanos, K. G. Beltsios, D. Fokas, C. P. Athanasekou and N. K. Kanellopoulos, J. Membr. Sci., 2010, 365, 366-377.

16 O. Tzialla, A. Labropoulos, A. Panou, M. Sanopoulou, E. Kouvelos, C. Athanasekou, K. Beltsios, V. Likodimos, P. Falaras and G. Romanos, Sep. Purif. Technol., 2014, 135, 22-34.

17 P. Scovazzo, D. Havard, M. McShea, S. Mixon and D. Morgan, J. Membr. Sci., 2009, 327, 41-48.

18 S. Hanioka, T. Maruyama, T. Sotani, M. Teramoto, H. Matsuyama, K. Nakashima, M. Hanaki, F. Kubota and M. Goto, J. Membr. Sci., 2008, 314, 1-4.

19 L. M. Santos, J. N. Canongia Lopes, J. A. Coutinho, J. M. Esperança, L. R. Gomes, I. M. Marrucho and L. P. Rebelo, J. Am. Chem. Soc., 2007, 129, 284-285.

20 P. Snedden, A. I. Cooper, K. Scott and N. Winterton, Macromolecules, 2003, 36, 4549-4556.

21 M. Kohoutova, A. Sikora, S. Hovorka, A. Randova, J. Schauer, M. Tisma, K. Setnicková, R. Petickovic, S. Guernik and N. Greenspoon, Eur. Polym. J., 2009, 45, 813-819.

22 S. Yoo, J. Won, S. W. Kang, Y. S. Kang and S. Nagase, J. Membr. Sci., 2010, 363, 72-79.

23 Y. He, P. G. Boswell, P. Bühlmann and T. P. Lodge, J. Phys. Chem. B, 2008, 111, 4645-4652.

24 T. Ueki and M. Watanabe, Macromolecules, 2008, 41, 37393749.

25 L. F. Zubeir, T. M. Nijssen, T. Spyriouni, J. Meuldijk, J.-R. Hill and M. C. Kroon, J. Chem. Eng. Data, 2016, 61, 4281-4295.

26 S. M. Mahurin, J. S. Lee, G. A. Baker, H. Luo and S. Dai, J. Membr. Sci., 2010, 353, 177-183.

27 S. M. Mahurin, P. C. Hillesheim, J. S. Yeary, D. E. Jiang and S. Dai, RSC Adv., 2012, 2, 11813-11819.

28 L. C. Tomé, C. Florindo, C. S. Freire, S. P. N. Rebelo and I. M. Marrucho, Phys. Chem. Chem. Phys., 2014, 16, 1717217182. 
29 O. Tzialla, C. Veziri, X. Papatryfon, K. G. Beltsios, A. Labropoulos, B. Iliev, G. Adamova, T. J. S. Schubert, M. C. Kroon, M. Francisco, L. F. Zubeir, G. E. Romanos and G. N. Karanikolos, J. Phys. Chem. C, 2013, 117, 1843418440.

30 I. S. Chae, S. W. Kang, J. Y. Park, Y. G. Lee, J. H. Lee, J. Won and Y. S. Kang, Angew. Chem., Int. Ed., 2011, 50, 2982-2985.

31 M. J. Frisch, G. W. Trucks, H. B. Schlegel, G. E. Scuseria, M. A. Robb, J. R. Cheeseman, G. Scalmani, V. Barone, B. Mennucci, G. A. Petersson, H. Nakatsuji, M. Caricato, X. Li, H. P. Hratchian, A. F. Izmaylov, J. Bloino, G. Zheng, J. L. Sonnenberg, M. Hada, M. Ehara, K. Toyota, R. Fukuda, J. Hasegawa, M. Ishida, T. Nakajima, Y. Honda, O. Kitao, H. Nakai, T. Vreven, J. A. Montgomery Jr, J. E. Peralta, F. Ogliaro, M. Bearpark, J. J. Heyd, E. Brothers, K. N. Kudin, V. N. Staroverov, T. Keith, R. Kobayashi, J. Normand, K. Raghavachari, A. Rendell, J. C. Burant, S. S. Iyengar, J. Tomasi, M. Cossi, N. Rega, J. M. Millam, M. Klene, J. E. Knox, J. B. Cross, V. Bakken, C. Adamo, J. Jaramillo, R. Gomperts, R. E. Stratmann, O. Yazyev, A. J. Austin, R. Cammi, C. Pomelli,
J. W. Ochterski, R. L. Martin, K. Morokuma, V. G. Zakrzewski, G. A. Voth, P. Salvador, J. J. Dannenberg, S. Dapprich, A. D. Daniels, O. Farkas, J. B. Foresman, J. V. Ortiz, J. Cioslowski, and D. J. Fox, Gaussian 09, Revision C.01, Gaussian, Inc., Wallingford CT, 2010.

32 A. D. Becke, Density-functional thermochemistry, Chem. Phys., 1993, 98, 5648-5652.

33 C. Lee, W. Yang and R. G. Parr, Phys. Rev. B, 1988, 37, 785789.

34 W. J. Hehre, L. Random, P. R. Schleyer and J. A. Pople, $A b$ initio molecular orbital theory, Wiley, New York, 1986.

35 C. Deverell, R. E. Morgan and J. H. Strange, Mol. Phys., 1970, 18, 553-559.

36 J. A. Steckel, J. Phys. Chem. A, 2012, 116, 11643-11650.

37 I. N. Yoon, S. Yoo, S. J. Park and J. Won, Chem. Eng. J., 2011, 172, 237-242.

38 J. Xi, X. Qiu, W. Zh and X. Tang, Microporous Mesoporous Mater., 2006, 88, 1-7.

39 J. Yoon, D. K. Kang, J. Won, J. Y. Park and Y. S. Kang, J. Power Sources, 2012, 201, 395-401. 